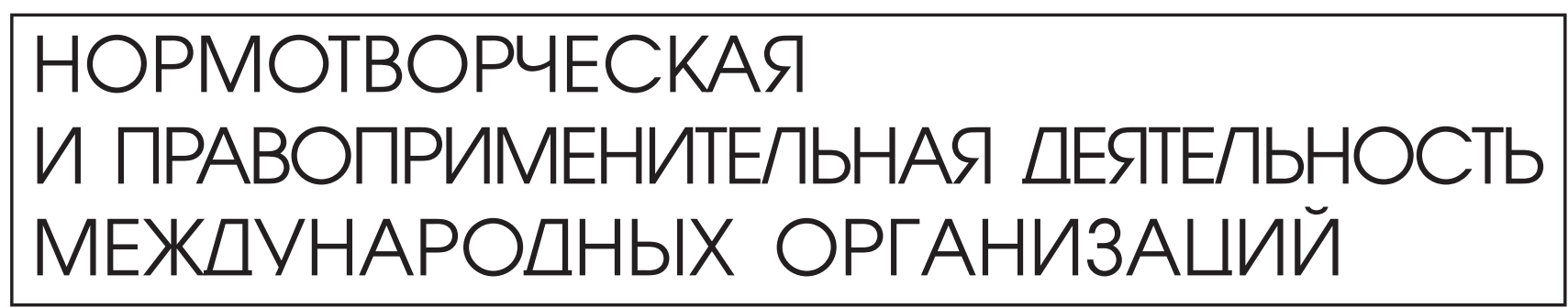

Кешнер M.B.

\title{
ЭКОНОМИЧЕСКИЕ САНКЦИИ ООН: ТЕНДЕНЦИИ РАЗВИТИЯ ФОРМ ОСУЩЕСТВЛЕНИЯ
}

Аннотация. Объектом исследования настоящей статьи являются вопросы сущности и содержания форм осуществления международных экономических санкиий, вводимых Советом Безопасности Организации Объединенных Наций на основании главы VII Устава ООН. Автор подробно анализирует международную практику форм осуществления международных экономических санкиий. Автор подробно рассматривает такие аспекты исследования как появление в последние два десятилетия новой формы осуществления экономических санкичии - «замораживание средств, или других финансовых активов или других экономических ресурсов», модификацию режимов адресных санкций. Методологическую основу настоящего исследования составили методы комплексного анализа, а также формально-юридический и сравнительно-правовой методы. Основными выводами исследования являются положения о универсальной пространственной сфере действия экономических санкиий, вводимых ООН, предель предметной сферы очерчены соответствующими резолюииями Советом Безопасности ООН. Автором обосновывается положение о тенденции в выборе форм осуществления международных экономических санкций в пользу форм, носящих ичеленаправленный и избирательный характер.

Ключевые слова: Международные экономические санкиии, формы осуществления санкиий, эмбарго, экономический бойкот, замораживание финансовых авуаров, экономическая блокада, Совет Безопасности ООН, ООН, Устав ООН, модификация санкционных режимов.

Abstract: The object of research in this article is the questions of essence and content of the forms of implementation of international economic sanctions issued by the UN Security Council based on Chapter VII of the UN Charter. The author conducts a detailed analysis of the international practice of the forms of implementation of international economic sanctions. A thorough examination is given to such aspects of research as a new form of implementation of economic sanctions that has emerged over the last two decades - "freezing of assets, or other financial products and economic resources". Among the main conclusions are the positions on universal sphere of effect of economic sanctions imposed by the UN, and the limits of the subject area that are demarcated by the corresponding resolutions of the UN Security Council. The author substantiates the position on the trend in the choice of the forms of implementation of international economic sanctions in favor of the forms that carry a targeted an elective character.

Keywords: UN Security Council, economic blockade, freezing of financial holdings, economic boycott, embargoes, forms implementation of sanctions, international economic sanctions, UN, UN Charter, modification of sanction regimes. 
$\Gamma$ лава VII Устава ООН предусматривает следующие виды санкций, предпринимаемых Советом Безопасности $\mathrm{OOH}$ «для поддержания или восстановления международного мира и безопасности»: «полный или частичный перерыв экономических отношений, железнодорожных, морских, воздушных, почтовых, телеграфных, радио и других средств сообщения, а также разрыв дипломатических отношений». Кроме того, «если Совет Безопасности сочтет, что указанные меры «могут оказаться недостаточными, он уполномочивается предпринимать такие действия воздушными, морскими или сухопутными силами, какие окажутся необходимыми для поддержания и восстановления международного мира и безопасности. Такие действия могут включать демонстрации, блокаду и другие операции воздушных, морских или сухопутных сил членов Организации». Заметим, что перечень мер, содержащихся в статье 41 главы VII Устава ОOH, не является исчерпывающим. Так, по мнению Ю.Н.Жданова, «многообразие международной жизни может вызвать новые специфические виды санкций» [1].

Таким образом, в арсенале применяемых Советом Безопасности ООН принудительных мер, учитывая их отличный характер, направленность, механизм введения, осуществления и окончания, юридические и фактические последствия применения, можно выделить дипломатические санкции, экономические санкции, военные санкции. Следует отметить, что международно-правовые санкции - это меры, применяемые в рамках системы коллективной безопасности государств. И.И.Лукашук (член Комиссии международного права ООН в 1994-2001годах) отмечал, что «ныне, как констатировала Комиссия международ- ного права ООН, термин «санкция» используется для обозначения принудительных мер, принимаемых международными организациями, особенно на основании главы VII Устава ООН» [2].

Статья 41 главы VII Устава ООН в качестве экономических санкций называет «полный или частичный перерыв экономических отношений». Анализ практики применения Советом Безопасности ООН указанных мер позволяет заключить, что реализация формулы «полного или частичного перерыва экономических отношений» предусматривает широкий диапазон форм осуществления, включающих в себя: эмбарго, бойкот, экономическую блокаду, замораживание финансовых ресурсов, включая средства, получаемые или извлекаемые благодаря имуществу, находящемуся во владении или под прямым или косвенным контролем объекта санкций, запрет капиталовложений в экономику объекта санкций, а также предоставление ему финансовой, материальной, технической и другой помощи.

Г.И.Курдюков включает в это перечень также приостановление или прекращение торговых договоров; полное или выборочное прекращение перевозок; отказ от режима наибольшего благоприятствования; отказ в поддержке международных программ помощи, пересмотр графика выплаты по долгам [3].

Существенным свойством, определяющим содержание экономических санкций и отличающим их от иных, предусмотренных Уставом ООН принудительных мер, является достижение целей введения посредством оказания воздействия на экономику объекта санкций[4]. В зависимости от вышеперечисленных форм осуществления экономических санкций 
подобное воздействие может носить как всеобъемлющий характер, например в случае введения экономической блокады, так и «направленный», сдерживая потенциальные возможности объектов санкций по развитию определенных отраслей производства, экономической инфраструктуры, ограничивая товарооборот конкретными группами товаров, инвестиционный режим.

Следует заметить, что подобные санкции, мотивируемые интересами обеспечения международного мира и безопасности, несомненно, имеют политический характер, однако их выражение или метод принуждения - экономический. Г.М.Вельяминов пишет: «Экономические по содержанию санкции, введенные Советом безопасности ООН в 1990 году против Ирака, в 1992 году - против Ливии, по существу нельзя, разумеется относить к санкциям именно экономическим (т.е. в рамках международного экономического права или, более узко, - системы ВТО)»[5]. В свою очередь, Б.Картер отмечает: «... экономические санкции могут быть определены как принудительные экономические меры, осуществляемые одним или несколькими государствами в целях изменения политики или демонстрации позиции государства относительно политики государства - объекта этих мер»[6].

Под эмбарго понимается прекращение или ограничение экспорта в государство, совершившее правонарушение. В зависимости от диапазона установленных запретов различают полное и частичное эмбарго. Полное эмбарго предусматривает прекращение всех экспортных поставок в государство, в отношении которого введен режим международных экономических санкций. Так, резолю- цией Совета Безопасности 661 (1990) в отношении Ирака было введено полное торговое эмбарго, предусматривающее запрет на экспорт товаров в Ирак, за исключением поставок, предназначенных исключительно для медицинских целей, продуктов питания и других предметов, необходимых для удовлетворения гуманитарных потребностей, которые должны были определяться Комитетом Совета Безопасности по санкциям, учрежденным указанной резолюцией[7].

Частичное эмбарго предусматривает ограничения в экспортных поставках отдельных видов сырья или продукции, которые, как правило, являются наиболее необходимыми для экономики государства, в отношении которого введен санкционный режим, или же способствовали или способствуют в настоящем совершению им дальнейших правонарушений.

Совет Безопасности использует в своей практике эмбарго на поставки оружия, нефти и нефтепродуктов, оборудования для переработки и транспортировки нефти. Введение Советом Безопасности $\mathrm{OOH}$ эмбарго на поставки нефти и нефтепродуктов имело место в отношении Южной Родезии, Анголы, Гаити, СьерраЛеоне; эмбарго на оборудование для переработки и транспортировки нефти - в отношении Ливии [8]. Впервые введение Советом Безопасности ООН эмбарго на поставки предметов роскоши имело место в отношении Корейской НародноДемократической Республики[9]. К предметам роскоши согласно резолюции были отнесены (драгоценности: ювелирные изделия с жемчугом, необработанные ценные минералы, драгоценные и полудрагоценные камни (включая алмазы, сапфиры, рубины и изумруды, ювелирные 
изделия из драгоценного металла или металла, плакированного драгоценным металлом; средства транспорта: яхты; автомобили (и другие транспортные средства) класса «люкс»: автомобили и другие транспортные средства для перевозки людей (помимо средств общественного транспорта), включая автомобили с кузовом «универсал»; гоночные автомобили

Важнейшую роль в предотвращении и прекращении вооруженных конфликтов выполняют вводимые Советом Безопасности ООН режимы эмбарго на поставки вооружений. Анализ резолюций Совета Безопасности ООН, позволяет заключить, что режим эмбарго на поставки оружия может предусматривать: запрет продажи оборудования и материалов, необходимых для ремонта, производства и использования оружия и военной техники; отказ в поставке запасных частей для оружия и военной техники; аннулирование всех лицензий и военных патентов, предоставленных ранее в целях производства оружия и боеприпасов, военного снаряжения и оказания технической помощи в целях производства оружия и военно-транспортных средств; запрет капиталовложений в производство оружия и военной техники; прекращение любой иной военной помощи, включая подготовку личного состава вооруженных сил государства-правонарушителя, консультаций или подготовки, связанных с военной деятельностью. Кроме того, осуществление эмбарго может включать запрет предоставлять транспортные средства для поставок товаров и грузов на территорию государства-объекта санкций.

Экономический бойкот в отличие от эмбарго предусматривает запрет на осуществление торговых импортных операций с государством-правонарушителем и его субъектами. Иными словами, государства прекращают или ограничивают импорт сырья, изделий или иного имущества, происходящего из государства-правонарушителя. Различают частичный и полный бойкот, критерием отличия которых выступает всеобъемлющий характер последнего[10].

Действие частичного бойкота предусматривает запрет на импорт отдельных видов или групп товаров, продукции, услуг. Например, в резолюции 1306 (2000) Совет Безопасности ООН постановил, что «все государства должны принять необходимые меры в целях запрещения прямого и непрямого импорта всех необработанных алмазов из Сьерра-Леоне на их территорию и просил правительство Сьерра-Леоне в срочном порядке обеспечить введение в действие в Сьерра-Леоне эффективного режима использования сертификата происхождения в торговле алмазами». Запрет на «ввоз на территорию всех государств в течение 10 месяцев круглого леса и лесоматериалов, поступающих из Либерии» введен резолюцией Совета 1478 (2003) [11].

В зависимости от круга лиц, на которых распространяется действие режима экономического бойкота, различают две его категории: первичный и вторичный. Режим первичного бойкота определяемый, в частности, как расширенный первичный бойкот, распространяет свое действие не только на юридических и физических лиц страны, участвующей в санкционном режиме, но в равной степени и на филиалы компаний, находящихся за границей, так и филиалы компаний, находящихся за границей, так и филиалы иностранных предприятий, контролируемых иностранными компаниями. 
Под вторичным бойкотом понимается запрещение государством самому ли его субъектам торговые операции в любой форме с субъектами третьего государства, которые, в свою очередь, осуществляют торговые операции с бойкотируемым государством или осуществляют иные запрещенные формы сношений (финансовая поддержка, дипломатическое признание) с государством, подвергнутым бойкоту [12]. Таким образом, если первичный бойкот касается государства-правонарушителя, вторичный - любого третьего государства, осуществляющего запрещенные связи с ним.

Экономическая блокада представляет собой комплекс всеобъемлющих мероприятий, направленных на изоляцию государства-правонарушителя со стороны третьих стран в различных сферах экономических взаимоотношений: торговых, финансовых, кредитных, складывающихся по поводу движения денежных средств, по передаче технологий и т.п. Режим экономической блокады в качестве составляющих компонентов может включать как меры эмбарго, так и бойкота.

Наиболее показательным примером масштабного осуществления международных санкций, являются введенные Советом Безопасности меры «по обеспечению выполнения Ираком пункта 2 резолюции 660 (1990) и восстановлению полномочий законного правительства Кувейта». Представляется, что столь детальная регламентация форм и способов прекращения экономических отношений с Ираком, были призваны обеспечить его полную экономическую изоляцию, а их содержание и характер позволяют говорить о проведении экономической блокады данного государства.
Экономические блокада и бойкот, в отличие от эмбарго, со всей очевидностью означают более строгую форму перерыва экономических отношений, о степени и масштабности воздействия которых как на экономику, так и в целом на государство-объект подобных санкций четко характеризуют следующие слова В.Уильсона: «Применяйте это экономическое, мирное, спокойное, неумолимое средство и не станет необходимости к применению силы. Бойкот - это замена войне» [13].

Широкое применение в последние годы в практике Совета безопасности ООН получила такая форма осуществления экономических санкций как «замораживание средств, или других финансовых активов или других экономических ресурсов».

Для целей осуществления финансовых запретов в рамках режимов международных санкций, вводимых Советом, «средства иди другие финансовые активы» включают: «финансовые активы и экономические блага любого рода, включая, в частности, наличность, чеки, денежные требования. Переводные векселя, платежные поручения и другие платежные средства; депозиты в финансовых учреждениях иди других организациях, остатки средств на счетах, задолженность и долговые обязательства; находящиеся в открытом и закрытом обороте ценные бумаги и долговые обязательства, включая акции, представляющие собой ценные бумаги, сертификаты, облигации, векселя, свидетельства, письменные долговые обязательства, контракты на производные финансовые инструменты; проценты, дивиденды или иные доходы на активы, либо накапливаемая за счет активов или 
создаваемая ими стоимость; кредиты, права зачета, гарантии; аккредитивы, коносаменты, купчие; документы, свидетельствующие об участии в средствах или финансовых ресурсах, и любые другие инструменты экспортного финансирования; слитки драгоценных металлов. Экономические ресурсы: активы любого рода, будь то осязаемые или неосязаемые, движимые или недвижимые, которые не относятся к категории средств».

Осуществление «замораживания средств» представляет собой недопущение любого передвижения, передачи, изменения и использования средств или распоряжения ими каким бы то ни было образом, которые приведут к любому изменению их объема, суммы, местонахождения, владения, принадлежности, характера, предназначения или к иному изменению, которое позволит использовать средства, включая управление ценными бумагами, но исключая накопление процентов по обоснованным коммерческим ставкам. «Замораживание экономических ресурсов» предусматривает недопущение их использования, в том числе для получения средств, товаров или услуг, любым образом, включая, в частности, использование путем продажи или закладывания [14].

Учитывая особенности вышеизложенных экономических санкций, объективно вытекающих из организационных форм их осуществления, интенсивности и влекомых последствий, вместе с тем представляется возможным дать им следующее определение. Международные экономические санкции представляют собой принудительные меры, вводимые международными организациями, прежде всего ООН, в целях обеспечения пресечения международных правонарушений и восстановления международного правопорядка, посредством оказания воздействия на экономику объекта правонарушителя.

В зависимости от типа международной организации, принявшей решение о применении международных экономических санкций, и характера самого решения международные санкции могут быть полными (универсальными) и (или) частичными (ограниченными) по предметной и (или) пространственной сфере. Международные экономические санкции, применяемые Советом Безопасности в соответствии с гл. VII Устава ООН, являются универсальными по пространственной сфере. Что касается предметной сферы, то ее пределы очерчиваются соответствующими резолюциями Совета. Например, международные экономические санкции, введенные Советом в отношении Сомали, являются универсальными по пространственной сфере, но их предметная сфера ограничена эмбарго на поставки оружия.

В случае если международные экономические санкции являются универсальными как по пространственной, так и по предметной сфере, они будут иметь абсолютный характер и означать полную экономическую изоляцию государства-правонарушителя. Для современного международного правопорядка принципиально важно санкционирование такого рода мер только ООН и, в частности, Советом Безопасности.

В заключение следует отметить, что формы осуществления международных экономических санкций модифицируются одновременно с развитием самой концепции санкционного принуждения, отражающей изменения характера международных угроз, фактор глобального углубления экономической взаимозависимости государств, а также учитывающей 
практические результаты осуществления Советом Безопасности режимов экономических санкций. Анализ практики применения Советом Безопасности экономических санкций позволяет с уверенностью говорить о тенденции смещения в выборе тех или иных форм осуществления санкций в пользу форм, носящих целенаправленных и избирательный характер, таких как частичное эмбарго, замораживание средств и иных экономических ресурсов объекта санкций.

\section{Библиография:}

1. Ю.Н. Жданов Принудительные меры в международном праве: Монография-М.: Диалог-МГУ.-1998.-С.41.

2. И.И. Лукашук Право международной ответственности //Международное публичное и частноеправо. -2002. -2. - С. 39-41. И.И. Лукашук Право международной ответственности-М.: Волтерс Клувер. - 2004. - С. 320.

3. Г.И. Курдюков Международные экономические санкции и права человека (применение в практике Совета Безопасности ООН) //РЕМП. Спец. Выпуск СПб. - 2000. - С. 101.

4. С.В. Маринич Экономические санкции в международном праве. Автореф. дис. канд. юрид. наук. - M., 1989. - С. 12.

5. .М. Вельяминов Международное экономическое право и процесс (Академический курс): Учебник. - М.: Волтерс Клувер. - 2004. - С.207.

6. B.E. Carter International Economic Sanctions Improving: The Haphazard US Legal Regime. - P.8.

7. Резолюция Совета Безопасности ООН S/RES/661 (1990), 6 august 1990. URL//http://www.un.org/ru/ documents/ods.asp? $\mathrm{m}=\mathrm{S} / \mathrm{RES} / 661 \% \mathrm{C} 2 \% \mathrm{A0}(1990)$

8. Резолюции Совета Безопасности ООН: S/RES/841(1993), 16 june 1993; S/RES/864(1993), 15 september 1993; S/RES/883 (1993), 11 november 1993; S/RES/232(1996), 16 december 1966; S/RES/1132(1997), 8 october 1997 URL//http://www.un.org/russian/sc/committees/.

9. Резолюция Совета Безопасности ООН S/RES/2094 (2013) URL//http://www.un.org/ru/documents/ods. asp? $\mathrm{m}=\mathrm{S} / \mathrm{RES} / 2094(2013)$.

10. W.H. Nelson and T.C.F. Prittie The Economic War Against the Jews. New York: Random House. - 1977. - P.29.

11. Резолюции Совета Безопасности ООН: S/RES/1306 (2000), 5 july 2000 URL//http://www.un.org/ru/ documents/ods.asp?m=S/RES/1306(2000); S/RES/1478 (2003), 6 may 2003 URL//http://www.un.org/ru/ documents/ods.asp? $\mathrm{m}=\mathrm{S} / \mathrm{RES} / 1478(2003)$.

12. D. Muiz The Boycott in International Law. - Journal of International Law and Economics. Vol. 9 (1974). - P.187; L. Lucchini Le boycottage - Aspects du droit International Economique. - 1972. - P. 67-101; J. L. Bismuth Le boycottage dans les echanges economiques internationaux. - 1980. - P.5-6.

13. Fried Grunfield The effectiveness economic sanctions UN. New York. - 1997. - P.31.

14. Пресс-релиз Комитета об осуществлении пункта 23 резолюции 1483 (2003) (документ ООН Press Release SC/7831, IK/372, 29 july 2003) URL//http://www.un.org/russian/sc/committees/1518/non_paper.shtml.

15. Кешнер М.В. К вопросу о проектах повышения эффективности международных санкций // Право и политика. - 2014. - 1. - С. 53 - 56. DOI: 10.7256/1811-9018.2014.1.9062.

16. Э. А. Калинин К вопросу об идеологических основах принципов международного экономического права и Россия как полноправный участник международных отношений // Право и политика. -2011. - 8. -C. 1323 - 1334.

\section{References (transliterated):}

1. Yu.N. Zhdanov Prinuditel'nye mery v mezhdunarodnom prave: Monografiya-M.: Dialog-MGU. - 1998. - S.41.

2. I.I. Lukashuk Pravo mezhdunarodnoi otvetstvennosti //Mezhdunarodnoe publichnoe i chastnoe pravo. -2002. -2. - S. 39-41. I.I. Lukashuk Pravo mezhdunarodnoi otvetstvennosti-M.: Volters Kluver. - 2004. - S.320. 
3. G.I. Kurdyukov Mezhdunarodnye ekonomicheskie sanktsii i prava cheloveka (primenenie v praktike Soveta Bezopasnosti OON) //REMP. Spets. Vypusk SPb. - 2000. - S. 101.

4. S.V. Marinich Ekonomicheskie sanktsii v mezhdunarodnom prave. Avtoref. dis. kand. yurid. nauk. - M., 1989. - S. 12.

5. G.M. Vel'yaminov Mezhdunarodnoe ekonomicheskoe pravo i protsess (Akademicheskii kurs): Uchebnik. - M.: Volters Kluver. - 2004. - S.207.

6. B.E. Carter International Economic Sanctions Improving: The Haphazard US Legal Regime. - P.8.

7. W.H. Nelson and T.C.F. Prittie The Economic War Against the Jews. New York: Random House. -1977. - P.29.

8. D. Muiz The Boycott in International Law. - Journal of International Law and Economics. Vol. 9 (1974). - P.187; L. Lucchini Le boycottage - Aspects du droit International Economique. - 1972. - P. 67-101; J. L. Bismuth Le boycottage dans les echanges economiques internationaux. - 1980. - P.5-6.

9. Fried Grunfield The effectiveness economic sanctions UN. New York. - 1997. - P.31.

10. Keshner M.V. K voprosu o proektakh povysheniya effektivnosti mezhdunarodnykh sanktsii // Pravo i politika. - 2014. - 1. - C. 53 - 56. DOI: 10.7256/1811-9018.2014.1.9062.

11. E. A. Kalinin K voprosu ob ideologicheskikh osnovakh printsipov mezhdunarodnogo ekonomicheskogo prava i Rossiya kak polnopravnyi uchastnik mezhdunarodnykh otnoshenii // Pravo i politika. $-2011 .-8$. - C. $1323-1334$. 